\title{
Can we settle the on-pump or off-pump debate with more than a million patients?
}

\author{
Derrick Y. Tam, MD, and Stephen E. Fremes, MD, MSc, FRCSC, FACP, FACC
}

\footnotetext{
From the Division of Cardiac Surgery, Department of Surgery, Schulich Heart Centre, Sunnybrook Health Sciences Centre, University of Toronto, Toronto, Ontario, Canada.

Disclosures: Authors have nothing to disclose with regard to commercial support.

Received for publication Aug 27, 2017; accepted for publication Aug 30, 2017; available ahead of print Sept 21, 2017.

Address for reprints: Stephen E. Fremes, MD, MSc, FRCSC, FACP, FACC, Dr Bernard S. Goldman Chair in Cardiovascular Surgery, Schulich Heart Centre, Sunnybrook Health Sciences Centre, 2075 Bayview Ave, Room H4 05, Toronto, Ontario M4N 3M5, Canada (E-mail: Stephen.fremes@sunnybrook.ca).

J Thorac Cardiovasc Surg 2018;155:180-1

$0022-5223 / \$ 36.00$

Copyright (c 2017 by The American Association for Thoracic Surgery

http://dx.doi.org/10.1016/j.jtcvs.2017.08.106
}

In this issue of the Journal, Filardo and colleagues ${ }^{1}$ present a comprehensive meta-analysis of randomized, controlled trials (RCTs) and observational studies comparing offpump with on-pump coronary artery bypass grafting (CABG). They are to be congratulated for their efforts in pooling more than 1.2 million patients from 42 RCTs and 31 risk-adjusted observational studies to examine both short-term and late mortalities. Filardo and colleagues ${ }^{1}$ found a $43 \%$ difference in the probability of early mortality in the off-pump arm compared with the on-pump group, driven by differences in the pooled observational studies. By 5 years, however, the difference in the probability of mortality was $10 \%$ higher in the off-pump arm, and it climbed to $14 \%$ by 10 years when examining only observational studies. Filardo and colleagues ${ }^{1}$ concluded that any short-term mortality benefit from the off-pump technique was lost in the long term.

Coronary artery disease remains the most common cause of death globally, and CABG remains the most effective mode of revascularization for those with extensive disease. Optimizing the surgical technique to improve outcomes remains a very relevant research question. There are more than 40 published meta-analyses that compare off-pump with on-pump CABG with a variety of study inclusion and exclusion criteria and subgroup analyses. This study represents the largest sample of patients used to compare off-pump with on-pump CABG. Filardo and colleagues ${ }^{1}$ painstakingly assessed all RCTs and observational studies with the Cochrane risk of bias tool; the final set of included studies were mostly at low risk for bias. This low risk was likely a result of their strict study inclusion criteria, requiring that observational studies adjusted for potential known baseline confounders of surgical risk. In addition, Filardo and colleagues ${ }^{1}$ appropriately performed sensitivity analyses to assess the impact of large studies by removing them from the analysis. This was an important step, because one of these large studies, from the Society of Thoracic Surgeons national database, constituted more than half of the

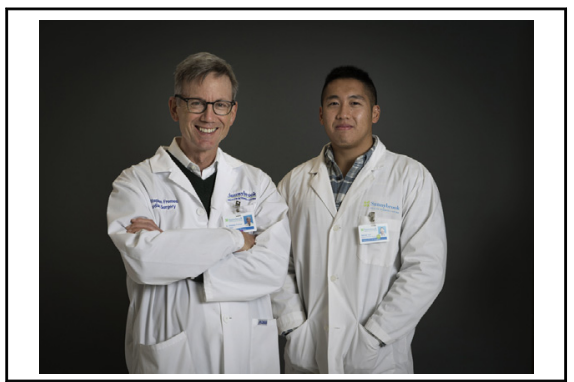

Stephen E. Fremes, MD, MSc, FRCSC, FACP, FACC (left), and Derrick Y. Tam, MD (right)

\section{Central Message}

Superior long-term outcomes can be achieved with on-pump coronary artery bypass grafting relative to off-pump coronary artery bypass grafting outside clinical trial settings.

See Article page 172 analysis population. Filardo and colleagues ${ }^{1}$ showed that the results were robust to the removal of this study. ${ }^{2}$

Nonetheless, this study must be interpreted in the context of some limitations. Two years have elapsed since the end date of the literature search. Since then, Lamy and associates $^{3}$ have published their 5-year outcomes from the CORONARY (CABG Off or On Pump Revascularization Study) trial, comparing off-pump with on-pump CABG in 4752 patients; they showed no difference in mortality (hazard ratio, $1.08 ; 95 \%$ confidence interval, 0.93-1.26). This publication was followed by the 5-year results from the ROOBY (Randomized On/Off Bypass) trial, which showed that off-pump $\mathrm{CABG}$ was associated with a higher risk of late mortality than was on-pump CABG (relative risk, 1.28 ; 95\% confidence interval, 1.03-1.58) in 2203 patients. $^{4}$

Articles were restricted to the English language, which potentially excluded important literature from non-English-speaking countries where off-pump CABG is the standard of care (particularly in Asia). This defect may be further exacerbated because Filardo and colleagues used PubMed as the only database; inclusion of Embase would have revealed additional studies. Certain high-risk subgroups (patients with low ejection fraction, elderly patients, and patients with other comorbidities, such as diabetes) were excluded; these are the very patients who potentially would benefit the most from off-pump CABG. $^{5-8}$ As such, the results of this study may only 
apply to the "general" CABG population with less comorbidity, as defined by Filardo and colleagues. ${ }^{1}$ Additional subgroup or metaregression analyses on surgeon experience or institutional volume with off-pump technique and on completeness of revascularization may lend insight regarding differences in late outcomes between RCTs and observational studies. This bias is largely mitigated in RCTs, particularly those trials restricted to only skilled or very experienced off-pump surgeons. This study reported only on the hard outcomes of early and late mortality. Additional important outcomes, such as stroke and repeated revascularization, were not reported, and such findings could potentially help explain the differences in early and late mortality between on-pump and off-pump CABG. ${ }^{9,10}$ In addition, a cumulative meta-analysis of studies by study year would have allowed Filardo and colleagues ${ }^{1}$ to evaluate era differences in outcomes.

Overall, this study adds to the growing body of work demonstrating that on-pump surgery remains a safe option for most patients requiring surgical revascularization. It is important to recognize, however, that off-pump surgery may be the preferred strategy in specific clinical scenarios. An analysis of the Society of Thoracic Surgeons national database from 1997 to 2007 showed that there were 38\% and $55 \%$ reductions in the odds of early mortality for patients undergoing off-pump operations in the third and fourth highest risk quartiles, respectively. ${ }^{11} \mathrm{~A}$ similar analysis of the same database from 2008 to 2011 of 25,667 patients with low ejection fraction $(<30 \%)$ found that the risks of death, stroke, and major adverse cardiac events were lower in the off-pump group, irrespective of institutional volume. ${ }^{12}$ The odds of stroke was $30 \%$ lower in a propensity-matched analysis of 6943 octogenarian patient pairs from the Nationwide Inpatient Sample. ${ }^{13}$ On-pump CABG with aortic crossclamping has been shown to increase the odds of a stroke by 2- to 4-fold relative to an anaortic off-pump technique. ${ }^{14}$ Finally, surgical experience in off-pump surgery matters. A propensity score-adjusted study of 13,226 patients from an institution with more than 15 years of experience in off-camp CABG found no difference in survival at 10 years or need for reintervention even though these patients received slightly fewer grafts (on-pump, $3.0 \pm 0.9$ vs off-pump, $3.3 \pm 0.9 ; P<.001$ ). ${ }^{15}$

As Filardo and colleagues ${ }^{1}$ correctly state in their article, RCTs address causation and are explanatory, whereas observational studies examine effectiveness of interventions in the real-world setting (as opposed to controlled settings). This study found that outcomes were not worse in RCT settings, yet late mortality was significantly higher in observational studies for patients undergoing off-pump CABG; this result further reinforces the importance of the multidisciplinary heart team to improve therapeutic decision making in individual cases. ${ }^{16}$ The heart team not only considers surgical risk but also accounts for vessel graftability, surgeon skill, and institutional outcomes with both surgical techniques, as well as the appropriateness of the hybrid revascularization option. Despite the inclusion in this meta-analysis of more than 1.2 million patients, the debate on the optimal surgical strategy for patients undergoing CABG will remain hotly contested. Nonetheless, Filardo and colleagues ${ }^{1}$ are to be commended on their efforts in examining both efficacy and effectiveness in a very comprehensive analysis.

\section{References}

1. Filardo G, Hamman BL, da Graca B, Sass DM, Machala NJ, Ismail S, et al Efficacy and effectiveness of on- versus. off-pump coronary artery bypass grafting: a meta-analysis of mortality and survival. J Thorac Cardiovasc Surg. 2018:155:172-9.e5.

2. Polomsky M, He X, O'Brien SM, Puskas JD. Outcomes of off-pump versus onpump coronary artery bypass grafting: Impact of preoperative risk. J Thorac Cardiovasc Surg. 2013;145:1193-8.

3. Lamy A, Devereaux PJ, Prabhakaran D, Taggart DP, Hu S, Straka Z, et al; CORONARY Investigators. Five-year outcomes after off-pump or on-pump coronaryartery bypass grafting. N Engl J Med. 2016;375:2359-68.

4. Shroyer AL, Hattler B, Wagner TH, Collins JF, Baltz JH, Quin JA, et al. Veterans Affairs ROOBY-FS Group. Five-year outcomes after on-pump and off-pump coronary-artery bypass. N Engl J Med. 2017;377:623-32.

5. Wang Y, Shi X, Du R, Chen Y, Zhang Q. Off-pump versus on-pump coronary artery bypass grafting in patients with diabetes: a meta-analysis. Acta Diabetol. 2017;54:283-92.

6. Kowalewski M, Pawliszak W, Malvindi PG, Bokszanski MP, Perlinski D, Raffa GM, et al. Off-pump coronary artery bypass grafting improves shortterm outcomes in high-risk patients compared with on-pump coronary artery bypass grafting: meta-analysis. J Thorac Cardiovasc Surg. 2016;151:60-77. e1-58.

7. Altarabsheh SE, Deo SV, Rababa'h AM, Lim JY, Cho YH, Sharma V, et al. Offpump coronary artery bypass reduces early stroke in octogenarians: a metaanalysis of 18,000 patients. Ann Thorac Surg. 2015;99:1568-75.

8. Wang Y, Zhu S, Gao P, Zhou J, Zhang Q. Off-pump versus on-pump coronary surgery in patients with chronic kidney disease: a meta-analysis. Clin Exp Neph rol. June 20, 2017 [Epub ahead of print].

9. Takagi H, Watanabe T, Mizuno Y, Kawai N, Umemoto T; ALICE (All-Literature Investigation of Cardiovascular Evidence) Group. A meta-analysis of adjusted risk estimates for survival from observational studies of complete versus incomplete revascularization in patients with multivessel disease undergoing coronary artery bypass grafting. Interact Cardiovasc Thorac Surg. 2014;18:679-82.

10. Takagi H, Mizuno Y, Niwa M, Goto SN, Umemoto T; ALICE (All-Literature Investigation of Cardiovascular Evidence) Group. A meta-analysis of randomized trials for repeat revascularization following off-pump versus on-pump coronary artery bypass grafting. Interact Cardiovasc Thorac Surg. 2013;17:878-80.

11. Puskas JD, Thourani VH, Kilgo P, Cooper W, Vassiliades T, Vega JD, et al. Offpump coronary artery bypass disproportionately benefits high-risk patients. Ann Thorac Surg. 2009;88:1142-7.

12. Keeling WB, Williams ML, Slaughter MS, Zhao Y, Puskas JD. Off-pump and onpump coronary revascularization in patients with low ejection fraction: a report from the Society of Thoracic Surgeons national database. Ann Thorac Surg. 2013;96:83-8; discussion 88-9.

13. Cavallaro P, Itagaki S, Seigerman M, Chikwe J. Operative mortality and stroke after on-pump vs off-pump surgery in high-risk patients: an analysis of 83,914 coronary bypass operations. Eur J Cardiothorac Surg. 2014;45:159-64.

14. Moss E, Puskas JD, Thourani VH, Kilgo P, Chen EP, Leshnower BG, et al. Avoiding aortic clamping during coronary artery bypass grafting reduces postoperative stroke. J Thorac Cardiovasc Surg. 2015;149:175-80.

15. Kirmani BH, Holmes MV, Muir AD. Long-term survival and freedom from reintervention after off-pump coronary artery bypass grafting: a propensity-matched study. Circulation. 2016;134:1209-20.

16. Yanagawa B, Puskas JD, Bhatt DL, Verma S. The coronary heart team. Curr Opin Cardiol. 2017;32:627-32. 